\title{
Poor South African Migrant Women and their Children's Education: Is there Hope After All?
}

\author{
Vuyisile Msila \\ PO Box 392, University of South Africa, College of Education, UNISA, 0003, South Africa \\ Email:msilavt@unisa.ac.za
}

\section{Doi:10.5901/mjss.2014.v5n14p546}

\begin{abstract}
The number of women who settle in urban areas from rural villages is growing in South Africa. The promise of a better life for these women in cities appears real. The government has done much in building low cost houses and bringing services to many poor families. However, as numbers burgeon, so does the demand for better life and essential services. This case study examines the experiences of eight women in educating their children in the city. They are all residents of Nene Informal Settlement where life has become hard. These participants were observed, shadowed and interviewed. Trying to feed their children, their stories reflect life of poverty and ill-health. With no full time jobs, they have no hopes of moving out of the squalor. However, the schooling of their children does not appear to be the ultimate solution to poverty. These poor women's homes lack social and cultural capital necessary to support the children. Yet, with no motivation and necessary resources, it appears as if the children will live the life of their mothers. The paper concludes by showing that unless these women change own their lives, they can never change the dire course of their children's journeys.
\end{abstract}

Keywords: Feminism. Parental involvement. Change agents. Poverty. School choice.

\section{Introduction: A woman's World}

There is much literature that reflects the immense role of women as change agents (Clarke, Wylie and Zomer 2013; Luchuo et al. 2013; UNHABITAT 2013). Women are powerful change agents when it comes to the utilization of the environment especially when they want to support their families. Yet poverty appears to be major in households where women are heads. The University of Western Cape Gender Equity Unit (UWC Gender Equity Unit) (1997) points out that women headed families are common among the black African population. Furthermore, this UWC Publication proclaims that female headed households are poorer than the average household. Around the world women are negatively affected by the corruption of the environment, especially the poor. With the rise of joblessness in South Africa, the poor women's circumstances are worsened by factors such as drought, declining health and the lack of land to produce.

One of the main obstacles for women is the challenge of not being able to gain from economy. Adeleye-Fayemi (2004) writes about the context of African feminism and the challenge women face. She points out that globalization has not helped the cause of women when it comes to economy. Furthermore, Adeleye-Fayemi argues that the globalization and implementation of economic policies have compounded the feminisation of poverty. "Global economic trends take local form in terms of loss of livelihoods, unemployment, trafficking in women, street children and a total rupturing of the social fabric that binds communities together" (Adeleye-Fayemi 2004, 39).

This article will explore the impacts of some of these.

Rodda (1997) refers to women as consumers of the natural environment. This author succinctly states:

\begin{abstract}
Women the world over are consumers of products and services which originated from the environment. In the household, women are consumers of energy and water, either directly or by the use of cookers, washing machines, refrigerators, and other domestic appliances. As household managers, women can control the use of the machines to minimize the consumption of fuel and water; as purchasers, they can select appliances, which are more economical of energy and water. (Rodda 1997, p.57)
\end{abstract}

The focus is on the poor women as managers of their families and how they endeavour to support their children in school. Poor women frequently work hard in supporting their children. Yet, more often than not, women face a number of obstacles in their role as consumers of the natural environment. Major obstacles include social and political constraints; educational constraints, the right to land and property; access to credit as well as access to technology (Rodda 1997). 
Some of these constraints are explored further in the paragraphs below. The main question explored is: What challenges do poor urban migrant women encounter as they try to educate their children in the city?

The sub-question asked is the following:

- Do cities present better life than the more challenging rural landscape?

\section{Brief Literature Review}

Among other roles, Rodda (1997) perceives the role of women as that of being educators, communicators and information specialists. Women conscientize the society about environmental awareness and they also help in sustaining change. "Women influence the entire family circle, and especially children, in their environmental perceptions, values and attitudes and in ethical considerations, as well as in the use of natural resources, energy consumption, and in waste and recycling" (Rodda 1997, p.104). Magnuson and Votruba-Drzal (2009) write about experiences in America when they state that about one in three children will experience poverty in childhood. Furthermore, these authors point out that 10 percent of the children will spend their childhood in this poverty and are more likely to be born into single-parent families, to mothers with low levels of education and to be black. The Equal Education (2011) writes about how in South Africa poverty is felt by black Africans in particular. They also add that households headed by women are twice as likely to be poor than male-headed households. Usually women also need natural energy to sustain their families. Cooked food, water, clean and healthy environment all emanate from energy. Oyedego (2012) argues that energy fuels productive activities including agriculture, commerce and manufacturing industry. Oyedego also points out that when there is lack of access to energy there will be poverty and deprivation which contribute to economic decline. Women need the access to energy if they want to play a meaningful role in society. The OECD DAC Network (GENDERNET) publication (2012) highlights that economic empowerment magnifies women's access to economic resources and opportunities. GENDERNET also argues that women's participation and empowerment are basic to strengthening women's rights and enabling women to have control over their lives and exert influence in society. The latter in South Africa is relevant as it is in line with the ideal cherished by the Constitution of the Republic of South Africa - to attain a democratic non-sexist country. Furthermore, GENDERNET contends that women's economic empowerment matters for pro-poor growth. Like Rodda's constraints cited above, GENDERNET (2012) declares that there are various specific challenges when working with the poorest women. These include:

- Lower levels of literacy;

- Lower levels of access to and control over resources;

- Lower levels of access to networks and people who can assist and support; and

- Greater vulnerability to sexual exploitation and abuse at the community level if not the household level.

No society can afford to live with these challenges. Clarke et al. (2013) argue that women and girls make up three fifths of the world's poor society hence attempts to defeat poverty have to address gendered norms and practices. "Several studies suggest that the benefits of promoting gender equality never berate widely, as women's empowerment yields economic, health, and educational benefits for families and communities" (Clarke et al. 2013, 59). Wise societies will concentrate on addressing gender inequality by emphasising and enhancing girls' and women's educational, political and employment access. Some authors such as Nickanor (2013) argue that for women who move from rural to urban settings become vulnerable to food insecurity. Hove, Ngweruma and Muchemwa (2013) support this when they also state that survival is the major concern for the urban poor and women and children are often the most vulnerable. Furthermore, Hove et al. (2013) write about how in urban setting children roam the streets as street children while some women can join the ranks of the informal economy especially when there are no prospects of employment. It is usually a disadvantage to the children when women lack education especially when it comes to health practices (Luchuo et al. 2013).

The poor women in urban settings usually lack resources that can address various aspects such as energy poverty. Balmer (2007) also argues that the country needs pro-poor policies that would address the challenge that women experience. Balmer also argues that the South African energy policies continue to fail poor women in South Africa.

\section{Research Methodology}

Purposive sampling was used in selecting the participants for this study. Eight women were selected from Nene Informal Settlement ${ }^{1}$, a relatively new unauthorised dwelling area in the Eastern Cape Province town of Port Elizabeth. In 
purposeful sampling the researcher is concerned with providing a sample of information-rich participants who show certain characteristics that the researcher is interested in. (Struwig \& Stead, 2004). The participants were selected because they were poor women who are originally from rural areas. They all came to Port Elizabeth to look for better economic opportunities. All these participants do not have any permanent employment and have children in school whilst in the city. The participants were interviewed and shadowed during the course of the study. The researchers were interested in examining the correlation between schooling and socio-economic status of women-headed families living in a squatter area.

Table 1 below shows the characteristics of the participants

\begin{tabular}{|l|c|c|c|c|}
\hline \multicolumn{1}{|c|}{ Name and Age } & Level of Education & Years in City & Children & Marital Status \\
\hline Anna, 33 & Grade 9 & 05 & 03 & Widowed \\
\hline Boniwe, 56 & Grade 10 & 08 & 05 & Widowed \\
\hline Dina, 39 & Grade 7 & 09 & 02 & Single \\
\hline Ivy, 50 & Grade 6 & 11 & 03 & Single \\
\hline Liza, 26 & Grade 11 & 03 & 01 & Single \\
\hline Sasa, 41 & Grade 6 & 07 & 03 & Married \\
\hline Sonto, 38 & Grade 12 & 09 & 04 & Single \\
\hline Violet, 40 & Grade 5 & 04 & 04 & Married \\
\hline
\end{tabular}

Table 1. Characteristics of participants

The researcher and two assistants shadowed the women for a period of three months. The participants were also interviewed and observed. The two research assistants were female postgraduate students who were well trained in shadowing and observation skills. However, only the chief researcher conducted the structured interviews with the participants. Shadowing schedules were negotiated with the participants beforehand, the researchers shadowed the women in their homes; they followed them to a few places where they went. The latter included the observations of interactions between the participants and their school going children. Shadowing took four days for each of the participants.

Five of the interviews were recorded with the participants' consent. Three participants objected from being audiorecorded. All the interviews were recorded in isiXhosa which is a dominant indigenous language in the Eastern Cape. These were then translated by the researcher who is a first language speaker of that language.

\section{The Findings}

The participants in the study reflected a number of challenges during the collection of data. The research assistants recollected how difficult it was to shadow the participants at times. Among the most challenging aspects experienced by the research assistants was the collection of firewood, fetching water from houses close by, as well as queuing for livestock entrails in long market queues. Sometimes after standing in the innards queue for a long time, the meat would be finished before the women bought theirs. One research assistant was also distraught after a visit to a municipal clinic where she felt that service needed much improvement. She cited long queues and that many patients went back home without being helped with the necessary medication. The shadowing results were enhanced by the interviews and observations.

During the interviews, the participants talked about a number of factors. They mentioned their hardships of living in poverty-stricken environment. Their lives are similar as they all struggle together in their neighbourhood. Many survive through small temporary jobs. Six of these women have children and are helped by the monthly child grants to sustain themselves. Each child receives a government grant of R200 a month (about 20 US dollars). Only Ivy and Boniwe do not receive child grant because their children are older than 18 . The menial jobs that all these women do from time to time include domestic duties such as baby sitting, ironing, cooking and general cleaning. Two have been temporary workers for three months in a local factory but that job had since ended. The women struggle to survive in the city and (the scarcity of) water, electricity and job opportunities are among the most frustrating aspects of living in an urban area. Almost all mentioned how difficult it was to educate their children because as parents they are not able to assist their children. All these hardships have an impact on the education of the children. I discuss the findings under four themes that emerged during the interviews. These themes are:

i. Struggle for good schools; 
ii. Lack of social and cultural capital;

iii. Ailing physical health; and

iv. Motivation to be at school.

\subsection{The struggle for good schools}

The main concern for the women in the study was their need to place their children in good schools. After the fall of apartheid, schools were desegregated, and many able parents started bussing their children to schools outside the historically black African areas or townships. In search of effective education, black African parents took their children to former white schools as well as private schools. Those who are economically able bus their children to what they regard as good schools. Some working-class parents do settle even for mediocre schools domiciled outside the townships. Under the apartheid dispensation these were either White, Indian or Coloured schools. The exodus is away from historically black African schools. Msila's (2005) research on this exodus shows how black African parents select schools by using criteria that is far from pedagogic reasoning. Discipline, English language skills were some of the qualities used by parents to choose what they referred to as good schools.

The participants in this study though are stuck in township schools and these are schools that are underperforming. All the participants would have liked to have their children studying in schools outside the townships had they had money. Boniwe says:

We all wish to have good education for our children. All of us know that township education does not work. There is usually no teaching in our schools. But with no money we cannot afford take our children to city schools.

Boniwe's words are echoed by Dina who points out:

Our children have no chance to free us from this poverty. The schools here do not do what they should be doing. Just a week ago my child told me there were only two teachers who went to their classrooms in three days. There cannot be proper education there. But what can one do?

These children in these underperforming schools are punished in a number of ways; by poverty as well as how their children will also be trapped in poverty in their adult years. Poverty has negative effects on a child's education. Driscoll and Nagel (2006) cite a United States of America's department of education's study which found that for every year a child spends in poverty, there is a chance that they will fall behind grade level by the age of 18 . Underperforming schools fail poor learners and middle class children perform better than their poor counterparts. Equal Education (2007, p.2) advance this argument as they contend:

This does not mean that learners from working class families cannot, or do not perform well in school. There are learners who perform well in school. There are learners who perform very well (in the same way that some learners from middle-class backgrounds perform poorly). Of course, this also does not mean that learners from poor communities have less potential than learners from middle class communities, or that they are less intelligent! They are just as bright and ambitious as learners from middle-class communities. But the education system has been failing them and they have to overcome many more obstacles in order to succeed.

Schools with no committed teachers, no resources, no culture of teaching and learning as well as crumbled management will add to the failure of poor children. Poor children in schools with no conducive climate are unlikely to move children out of poverty. The paradox of the desegregation of schools in South Africa is that as middle class families moved their children away from township schools, they left behind poorly performing schools and parents with no voice or social capital remain in these schools.

\subsection{Lack of social and cultural capital}

The participants reiterated that their children might not be doing well at school because their families do not have the necessary resources such as books and television as well as capable people to help with school work. These participants appeared to be saying that schools should do all teaching and not expect much help from parents at home. The parents maintained that teachers in schools "should do 90 percent of the work because schools have teachers who are better qualified". Pellino (2010, p.4) contends: 
Children from poverty start out in life at a disadvantage. Their mothers may have no or inadequate pre-natal care. They may have insufficient early health care. If the parents are fortunate to have jobs, affordable day care may be of poor quality (Slavin, 1998). Additionally, poor children do not have the same kind of experiences of other social classes do. The experiences they miss out on are those that could help in the development of skills and academic achievement. Some examples would be the use of home computers; visits to zoos and museums; attendance at pre-school programs.

These characteristics were shared by the sample of families in the study. The women in the sample shared a number of challenges that they experience as migrants in the city. Nene Informal Settlement is a new area that does not have the necessary infrastructure such as running water and toilets. The women struggle to sustain themselves and their families in such an environment. They struggle to cook; they collect wood near a farm that has a bushy area. Three of them use paraffin stoves as well for cooking. Although all of them usually pay a visit to their rural homes, they want to make it in the city, where they ironically declare, "it is where the bright lights are". Sasa who has been in the city for seven years now states:

I have been in the city for seven years now. My name is somewhere in the list of those who might get houses. It is tough though, for sometimes you wait forever whilst others get on the list after you do, but they get houses long before you do. Look at this place, no water, no toilets, no electricity. It is a scary place to have your children travel after dusk. But we have no choice, we call this place home.

All the participants concur that the land where their shacks are built are not on good land. It is hard clay which floods water when it rains. They say that they worry when the rain falls. Their area has no drainage system. Diseases and health problems frequently irk the community who usually find themselves defenceless to the health hazards. Ivy lives in a zinc iron shack with no big windows for ventilation. She says:

Living is difficult. We become sick with our children. When it is cold you find you do not have paraffin to heat your shack. When it is too hot - there is no fresh water. I wish that our government can address our needs. I've been in PE for more than ten years. I have no house still.

The participants belaboured the point that they did not have means to own anything. The women try hard to attain self-efficiency but with no jobs, no support and no money they find this difficult. All have no access to necessary amenities with the nearest clinic about twenty five kilometres away. The participants maintain that their lives have not changed for the better although the government has done many changes in some communities. Annecke (no date) argues that the struggle for democracy in South Africa has put women's rights in the public arena. The poor women lose their role as managers in their homes. However, "the need to include women in the quest for sustainable development is being recognized as regards both their knowledge and are biomes sans their role as caretakers of household consumption patterns" (Annecke nd). Annecke though also adds that women suffer from not having access to electricity and commercial fuels. Oyedego (2012) also contends that energy and poverty reduction are connected to the socioeconomic development which includes productivity, income growth, education and health. In Nene poverty is rife and health is exacerbated by condition created by squalor. Women are also exposed to numerous major obstacles.

It is largely due to the lack of resources that poor children do not succeed in school. Equal Education's (2011) Youth Group Sheet 5 contends that poor children often come from homes where there are few or no books. Furthermore, this publication declares that these working-class homes do not have a 'culture of reading'. The lack of social and cultural capital in working class homes ensnares poor families in the poverty trap. Pellino (2010) explains how children from poor families have little control over their environments. This author points out that, "the living environments and the culture of poverty often leave poor children with low levels of motivation to learn. Besides the fact that all of their energies may be directed elsewhere in their struggle to survive, they may have poor experiences with schooling or may perceive that they don't really need school to be successful" (Pelleno, 2010, p.4). The participants talked about how their boy children tended to hate school, dropped out easily to find various ways of making money. The absence of cultural and social capital is a heavy burden on the poor children who tend not to appreciate school because schools display a different world and different cultures. Soon poor children learn that education is not necessarily the equalizer that the society would like it to be. The parents can also see how their children fail in school. The participants in the study saw how the poor schools failed their children as achievement gap grew between them and the affluent. Physical health briefly mentioned above aggravates the circumstances of the poor. 


\subsection{Physical health}

With no medical insurance or employment, many participants highlighted that frequently their health and that of their children deteriorates. When they are sick some children do not go to school because they look after them. When the children are sick they also miss school, sometimes for months. Magnuson and Vitruba-Drzal (2009) assert that growing up in poverty is associated with illnesses. When poor children are compared with the upper income children, poor children are compared with the upper income children, poor children are reported to have the worse overall health. In countries such as the United States of America children from poor families have been found to have higher rates of chronic conditions such as asthma, diabetes and hearing, vision and speech problems (Magnuson \& Votruba-Drzal, 2009). There are many poor children who do not make it at school because of ill-health. The participants reiterated how illnesses prevented their children from enjoying life in general. Tuberculosis is the dominant illness in Nene.

Woolard (2002) perceives poverty, morbidity and mortality as linked. This author adds that the poor have difficulties in accessing healthcare because they do not have income for transport, food and basic clothing. In fact, children from impoverished families begin life at a disadvantage. Pellino (2010) contends that their mothers may have no pre-natal care and these children may have inadequate early health care. The participants pointed out that the clinic is distant from their area. When the women are pregnant, they rarely visit ante-natal clinic. Sonto says that when she was pregnant she used services of an elderly woman they call a voetvrou. This elderly woman would rub her tummy once a week during her term of pregnancy. She also would give her a traditional mixture believed to be effective for the mother and the unborn. Yet the children's sicknesses pervaded with many having indelible effects on schooling. Driscoll and Nagel (2006, p.3) affirm:

For children of all ages, poverty has some devastating effects. Poor children are two times more likely than nonpoor children to have stunted growth, iron deficiency, and severe asthma. A government study in 1996 showed that poverty placed children at greater risk of dying before their first birthdays than did a mother's smoking during pregnancy...For parents struggling to raise a child, poverty adds extensive stress to the family. McLoyd (1990) states that economic hardship experienced by lower-class families is associated with anxiety, depression and irritability.

The participants highlighted illnesses that hit the adults such as high blood pressure, depression and diabetes. All these negatively impacted on the children's well-being. These parents usually raise children who struggle at school because they are stunted. Stunting is one condition linked to poverty in South Africa and is usually caused by malnutrition (Equal Education, 2011). This publication also postulates that 25 percent of black African children display signs of stunting.

Improving women's education is very crucial for the advancement of families in society. When women have the necessary information they will be able to withstand other challenges such as health problems. Rural and poor women need education to transform their lives. Leeson (2004) cites Msimang who has declared that like healthcare, housing and employment, education is a service that is necessary for a world that must be struggled for. There are a number of factors that require education for women to survive. Economic stability, ways of conserving energy, improving healthcare as well as understanding various societal dynamics need education. Tax (1999) affirms that there are pressures in some societies to deny women of any kind of education. As a result of this, women become illiterate hence they languish in poverty. We find the same kind of illiteracy in rural areas and townships in South Africa. Women without education hardly have a voice. For women to be politically and socially aware, they need education. Usually programs for women's economic development, education and political equality bow to patriarchal culture.

The other major obstacle highlighted by the participants is ill health. Women in the study complained about ill health which makes it necessary for them to visit the clinic frequently. High blood pressure, diabetes and tuberculosis (TB) are among the illnesses that are rife in Nene Informal Settlement. Five participants are suffering from high blood pressure and two of the participants once had TB. III health is a major obstacle to migrant women wanting to survive in the city. The UWC Publication underscores that poor black African children's poor health has a direct bearing on the health standard of their mothers. "With women making up more than half the population there is an increasing realisation that an improvement to women's health is an improvement to the health of all" (UWC 1997, p. 54). III health creates new pockets of poverty among poor women. Dhanraj, Misra and Batliwala (2004, p.82) postulate:

Poverty also affects women's health and educational opportunities in both direct and indirect ways: long treks for basic needs deplete women's already low nutrition reserve and increase the opportunity costs of education, healthcare and participation in community life. Inadequate food and water, and cultures that enforce silent suffering, mean women develop a range of chronic diseases such as TB, anaemia and reproductive tract infections that go untreated. 
Poor health is a limitation to the poor who would like to try and shirk poverty. The situation of poor health affects the children. Research has shown that it is difficult to teach a hungry and an unhealthy child. Nene Informal Settlement does not have the necessary infrastructure that would support good health. One would however, wonder whether women are so helpless that they cannot stand on their own. All these health problems have an impact on motivation to learn which is now discussed.

\subsection{Motivation to be at school}

With all the problems that the participants experience one of their biggest challenges is to motivate their children to go to school. Violet and Liza talk about how difficult it is to convince their children to go to school. Children who live in poverty may fear school because they are different from fellow learners. The participants intimated how difficult it is to motivate their children who have old grey pants and shoes. The latter is a challenge to poor families; motivating children to be at school and learn. Abraham Maslow's theory of needs talks about the need to address basic needs if one is to fulfil the next set of needs. Hungry children cannot be motivated to learn. Maslow's theory talks about the need for people strive to be the best. This theory mentions a hierarchy of needs that needs to be actualized. According to the theory within every individual there are needs priorities. Each represents a level of personal functioning; the lower needs have to be fulfilled before the growth needs or higher needs are fulfilled (Hamachek, 1995). A hungry child needs food and can hardly be motivated to learn until he eats. Equal Education (2011) applauds the South African government for giving money and food to poor schools; however, even these are not enough to narrow the gap between rich and poor schools. The poor are not receiving good quality education in many public schools. As a result, nothing motivates these learners from poor communities. For the poor, school brings no hope for a better life.

Another factor that influences the children is parent involvement and the achievement belief. Although when interviewed all the participants showed eagerness to see their children succeed in education none of them are really "pushing" their children to achieve in school. The parents are not modelling what they want their children to attain. They might not be having this capacity but to the children this might appear as apathy. Their apparent apathy though should be linked to their day-to-day living. Searching for food and warm shelter are more important to these parents than homework for example. Yet, Wells (1996) states that parent involvement and the achievement ideology are closely linked because the learners tend to adopt their parents' ideology with regard to achievement. Furthermore, the parents' ideology and their involvement are closely linked.

However, more needs to be done to raise the motivation of poor learners. Individual parents might not do it alone as long as they live within a community with certain values and beliefs towards education. Therefore, there is a need to move beyond empowering few parents. Fine (1993, p.709) argues:

Parental involvement is necessary but not sufficient to produce improved student outcomes. Without a serious national, state, and community commitment to serving children broadly, and to restructuring schools in low income neighbourhoods and their surrounds deep parental involvement with schools will do little to positively affect or sustain low-income students or their schools or outcomes.

Motivating the poor children should be a continuous community project that would include parents. Furthermore, Fine (1993) postulates that unless the parents are organized as a political body, parental involvement projects will devolve into a swamp of crisis intervention.

\section{Conclusion}

This study has shown how the circumstances of migrant women hamper their attempts to educate their children in cities. Poverty, lack of education, lack of parental involvement and obstacles of a patriarchal society are some of the hindrances that prevent poor women from supporting the schooling of their children. The women's detachment from the economic activity does not make the urban area to be better than the rural area from whence they came from. Poverty is social injustice that condemns these women's families. These women are overwhelmed by many challenges associated with poverty and they fail to appreciate education of their children. Adeleye-Fayemi is supported by Kerr (2004) who is calling for feminists to seek alternative economic models for the future. Kerr contends that globalization can only be truly achieved if progressive male colleagues can show that another world is possible. This world is a world of economic justice where women are empowered to tackle the causes of poverty and disempowerment. Women are not better off today as evident in this study. The UWC Publication states that women still hold a disadvantaged position although they 
have gradually been moving into non-traditional careers. "South African women and black women in particular are affected by high levels of unemployment, a situation which is compounded by their reduced access to education and job training" (UWC 1997, p.66). Economy is linked to education. The women in the study pointed out that they struggle mainly because they do not have the necessary education that would enable them "to be aware of the world around."

The migrant women in the study demonstrate numerous challenges in the city. As highlighted above, among these are lack of education, lack of economy participation, being landless and ill health. Many left their villages in rural areas hoping to make it in the urban area, only to find new challenges coming up. None of the women in the study felt that the urban area is better than the rural areas. However, they appear to live "in the hope that someday there will be light". Yet nothing is going well for these women as their children are victims of ills health, they themselves have numerous illnesses. The women are aware that their families will never escape the poverty cycle because many older children in Nene have not completed schooling and are struggling to secure jobs, like their mothers.

\section{References}

Adeleye-Fayemi, B. (2004). Creating a new world with new visions: African feminism and trends in The global women's movement. In J. Kerr., E. Sprenger., \& A. Symington (Eds.), The future of women's rights: Global visions and strategies (pp. 38-55). London: Zed Books.

Annecke, W.J. (no date). Women and energy in South Africa. [Online] Available: http://www.energia. org/fileadmin/files/media/reports (March, 11, 2014)

Balmer, M. (2007). Energy poverty and cooking energy requirements: the forgotten issue in South African energy policy? Journal of Energy in Southern Africa, 18(3), 4-9.

Clarke, S., Wylie, G., \& Zomer, H. (2013). ICT 4 the MDGs? A perspective on ICT's role in Addressing urban poverty in the context of the Millennium Development Goals. Information Technologies \& International Development, 9(4), 55-70.

Dhanraj, D., Misra, G., \& Batliwala, S. (2004). An action framework for South Asia. In J. Kerr., E. Sprenger., and A. Symington (Eds.), The future of women's rights: Global visions and strategies (pp. 80-96). London: Zed Books.

Driscoll, A., \& Nagel, N.G. (2006). Poverty and the effects on children and parents. [Online] Available: http://www.education.com/print/ poverty-effects-children-parents/ (January 23, 2014)

Equal Education. (2011). Poverty and education. Youth Group Fact Sheet 5.

Fine, M. (1993). [Ap]parent involvement: Reflections on parents, power and urban public schools. Teachers College Record, 94, 682-710.

Hamachek, D. (1995). Psychology in teaching, learning, \& growth. Boston: Allyn and Bacon.

Hove, M., Ngwerume, E.T., and Muchemwa, C. (2013). The urban crisis in sub-Saharan Africa: A threat to human security and sustainable development. Stability, 2(1), 1-14.

Kerr, J. (2004). From 'opposing' to 'proposing': finding proactive global strategies for feminist futures. In J. Kerr., E. Sprenger., \& A. Symington (Eds.), The future of women's rights: Global visions and strategies (pp.14-37). London: Zed Books.

Leeson, R. (2004). Gender equality advocates speak: Feminist issues and strategies in the future. In J.

Kerr., E. Sprenger., \& A. Symington (Eds.), The future of women's rights: Global visions and strategies (pp. 197-212). London: Zed Books.

Luchuo, E.B., Paschal, K.A., Ngia, G., Njem, P.K., Yelena, S., Nsah, B., \& Ajame, N. (2013).

Malnutrition in Sub-Saharan Africa: burdens, causes and prospects. Pan African Medical Journal. [Online] Available: http:www.panafrican-med-journal.com/content/article/15/120/full (March 07, 2014)

Magnuson, K., \& Votruba-Drzal, E. (2009). Enduring influences of childhood poverty. Focus, (26(2), 32-37.

Msila, V. 2005. The education exodus: The flight from township schools. Africa Education Review, 2(2), 173-188.

Nickanor, N.M. (2013). Women and urban food insecurity in Southern Africa. Backgrounder, 55(3), 1-8.

OECD DAC Network. (2012). Women's economic empowerment: The OECD DAC Network on Gender Equality. GENDERNET.

Oyedego, S.O. (2012). Energy and sustainable development in Nigeria: the way forward. Energy Sustainability and Society, 2-17.

Pellino, K.M. (2010). The effects of poverty on teaching and learning. [Online] Available: http://www.teach-nology.com/Articles/ teaching/poverty/ (September 14, 2010)

Rodda, A. (1997). Women and the environment. London: Zed Books.

Struwig, F.W., \& Stead, G.B. (2004). Planning, designing and reporting research. Cape Town: Pearson Education.

Tax, M. (1999). Power of the word: Culture, censorship, and voice. In J. Silliman., \& Y. King (Eds.), Dangerous intersections: Feminists perspectives on population, environment, and development. Cambridge: South End Press.

UWC Gender Equity Unit. (1997). Beyond Inequalities: Women in South Africa. Bellville: UWC/SARDC.

UN Habitat. (2013). State of women in cities 2012-2013: Gender and the prosperity of cities. Nairobi: UN- Habitat.

Wells, A.S. (1996). African-American students' view of school choice. In B. Fuller., R.F. Elmore and G. Orfield. Who chooses? Who loses? Culture, institutions, and the unequal effects of school choice (pp. 25-49). New York: Teachers College Press.

Woolard, I. (2002). An overview of poverty and inequality in South Africa. Working Paper prepared for DFID (SA), July 2002. 